\title{
Cultura de mar. \\ Pesca artesanal en El Realejo desde la Antropología Visual
}

\section{Culture of the sea. Artisanal fishing in El Realejo from the Visual Anthropology}

Nelson Gabriel García Mendoza

Recibido: 14-04-2018

Estudiante activo IV año Licenciatura en Antropología Social.

Universidad Nacional Autónoma de Nicaragua, UNAN-Managua

ORCID ID: https://orcid.org/0000-0003-2076-7180

gabriel.antropologia96@gmail.com

Aceptado: 22-08-2018

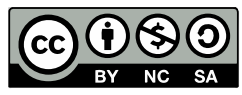

\section{Resumen}

El Realejo, debido a sus características biogeográficas permite a los pobladores realizar diferentes actividades económicas entre estas cortar mangle, extracción de concha y punche, pesca artesanal siendo esta la de mayor productividad, todas vinculadas al ecosistema costero. La pesca artesanal es para el Realejeño la actividad económica de mayor auge, debido a las condiciones que el entorno ecológico presta. Son numerosas las familias que se dedican a esta actividad, donde es notable la división sexual y social del trabajo debido a construcciones sociales establecidas, donde los jóvenes son encargados de ejercer fuerza física en la esfera productiva y la mujer un papel administrativo. El ser pescador implica de gran adaptación al ambiente marítimo. El proceso productivo implica búsqueda, detección y captura, para esto el pescador se apoya de la red de trasmallo, considerado el principal medio de producción para pescar, por otra parte, a partir de este instrumento se emplean diferentes artes de pesca. El objetivo del presente álbum, mediante sus fotografías es dar a conocer y explicar el proceso productivo llevado a cabo por los pescadores, el cual es determinante en la vida económica de esta localidad.

Palabras clave: pesca artesanal, proceso productivo, ecosistema costero, ambiente marítimo, económico.

\begin{abstract}
The Realejo, due to its biogeographic characteristics, allows the inhabitants to carry out different economic activities among these mangrove cut, shell and punche extraction, artisanal fishing being the one with the highest productivity, all linked to the coastal ecosystem. Artisanal fishing is for the Realejeño the economic activity of greater height, due to the conditions that the ecological surroundings lend are numerous the families that dedicate themselves to this activity, where it is remarkable the sexual and social division of the work due to established social constructions, where young people are responsible for exercising physical force in the productive sphere and women an administrative role. Being a fisherman implies a great adaptation to the maritime environment. The productive process involves search, detection and capture, for this the fisherman relies on the net of trammel considered the main means of production to fish, on the other hand, from this instrument different fishing gears are used. The objective of the present album, through its photographs, is to make known and explain the productive process carried out by the fishermen, which is a determining factor in the economic life of this town.
\end{abstract}

Keywords: artisanal fishing, productive process, coastal ecosystem, maritime, economic environment 
E Realejo, pueblo del Occidente de Nicaragua, se encuentra ubicado a $140 \mathrm{Km}$ de la ciudad de Managua, muy cercano a la carretera que une al departamento de Chinandega con Corinto, actual puerto de Nicaragua. El Realejo por división política administrativa pertenece al departamento de Chinandega región noroccidental de Nicaragua. El municipio se divide en cuatro zonas, en la zona número cuatro se encuentra el casco urbano conformado por los repartos: 25 de Febrero, Nuevo Amanecer, Germán Omier, Realejo Norte, Realejo Sur y Carolina Santana, las otras tres zonas conformantes son comarcas rurales entre ellas, Alemania Federal, La Báscula y La Chocolata.

El Realejo según datos (Alcaldía Municipal, 2005) tiene una población aproximada de 14,500 habitantes en un área de $105 \mathrm{~km} 2$, está situado entre las coordenadas $12^{\circ} 32^{\prime}$ de latitud norte y $87^{\circ} 10^{\prime}$ de longitud oeste con una distancia a la cabecera departamental de 11 Kilómetros, limita al norte con Chinandega y El Viejo, al sur con municipio de Corinto, al este con municipio de Chichigalpa y al oeste con el Océano Pacifico. La comunidad pesquera de El Realejo se caracteriza por una división sexual y social del trabajo, los hombres se encargan de la obtención de los productos del mar, mientras que la mujer resulta ser más emprendedora teniendo un papel activo en la administración del capital y comercialización del producto.

El proceso productivo en la pesca Realejeña se configura en: a) jornada y organización, b) medios de producción, c) técnicas, entre otras categorías. La unidad de producción básica y prácticamente existente consta de una lancha de motor fuera de borda y de dos pescadores. Los Realejeños consideran la pesca artesanal como una ocupación masculina, pues el proceso de captura demanda de mayor dureza, también debido a la tradicional división sexual del trabajo.

La faena cotidiana inicia en diferentes horarios, el cálculo del horario laboral del pescador es complejo, tanto la salida como regreso sea por la mañana o tarde varía, un aproximado de las horas laborales es de 5 a 6 horas, esta variación va en dependencia de las condiciones climáticas del contexto, debido al contacto con el ecosistema costero. Por lo tanto, el pescador no tiene un horario establecido.
El pescador durante la mañana o tarde antes de salir a faenar lleva a cabo la organización de sus medios productivos, esto implica el uso de instrumentos de pesca como de herramientas auxiliares, los instrumentos abarcan las líneas de redes de nylon, mientras las herramientas abarcan utensilios necesarios.

Cada lancha de motor es ocupada por dos pescadores: uno se encarga de manejar (capitán) y el otro de apoyar en las redes (marinero). Posterior a la organización de los medios productivos y documentos, se visualizan los destinos de pesca, puestos en marcha se supervisa las condiciones climáticas del ecosistema costero, para empezar a deducir que puntos de pesca favorecen en la faena. Este trayecto abarca el pasar por una serie de manglares donde la experiencia del conductor es importante, debido a las raíces y espacios angostos se dificulta lograr estabilidad de la lancha. El trayecto hasta dar con algunos de los puntos de pesca puede durar de una hora a dos horas, durante ese lapso se visualiza el ecosistema y se van deduciendo las técnicas a utilizar en función de los puntos de pesca. El pescador porta consigo termos donde lleva comida o alguna bebida, etc.

Una vez precisado y ubicados en los puntos de pesca, el pescador dispone de desplegar la red de trasmallo, donde ejecuta diferentes técnicas de pesca como tirar al rol, rodeado, cimbreada entre otras, para realizar esto el pescador con experiencia se guía por los indicios ecológicos y marinos: movimiento de la marea, la luna, dirección del viento. Guiándose por esto el pescador extiende la red de trasmallo en el mar, estando desplegada, esta operación dura de una a dos horas, al cabo de este tiempo la red se iza y se extraen las capturas depositándose en el contenedor con hielo.

Por otra parte, mientras el pescador considere que la especie no es peligrosa y sin detenerse tanto en el tamaño o peso de la captura siempre depositan el pescado en el contenedor, a pesar de que el pescador Realejeño faena en mar, sus volúmenes de producción, pesos de captura, tamaño de captura no es de mayor volumen como la pesca en Corinto y otros lugares.

Los pescadores luego de faenar se dirigen al acopio para negociar con la encargada, en algunos casos los une un nexo de parentesco, en otros solo relaciones de reciprocidad económica. La mayoría venden sus cap- 
turas al acopio, una de las actividades productivas en la localidad es dedicarse a la compraventa de productos del mar, a como se mencionó en su mayoría son mujeres las encargadas de este proceso, esto indica la división sexual del trabajo al mismo tiempo responde a una lógica económica pues resultan ser más dinámicas para ofrecer los productos. El pescador como productor principal establece relaciones económicas de compraventa que le permitan comercializar la captura para obtener sus ingresos económicos.

\section{Nelson Gabriel García Mendoza}

Nacionalidad nicaragüense. Egresado en 2014 de la Escuela Politécnica de Comercio con un Técnico en Mantenimiento y Reparación de Computadoras. Estudiante activo de IV año de la Licenciatura en Antropología Social en la Universidad Nacional Autónoma de Nicaragua UNAN- Managua. Reconocimiento de excelencia académica en los años 2016 y 2017. Ponente en la Jornada Universitaria de Desarrollo Científico (JUDC 2015- UNAN, Managua). Ponente en el Foro Estudiantil Latinoamericano de Antropología y Arqueología FELAA, sede en Barquisimeto, Venezuela del 9 al 13 de julio 2018. Fotógrafo aficionado. 


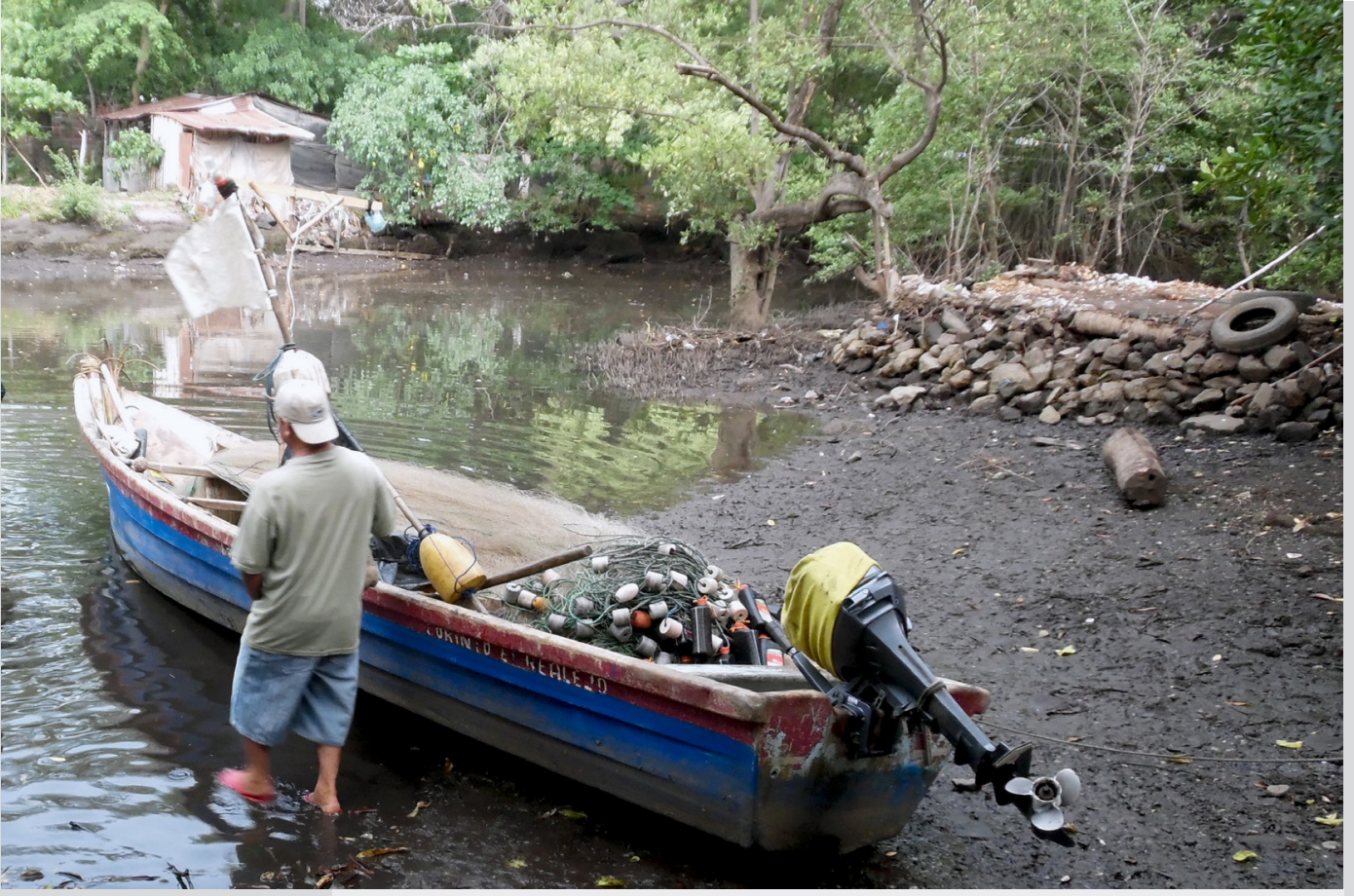

Pescador listo para salir a faenar, consigo lleva, trasmallo, visuales, termo con hielo y herramientas auxiliares. Municipio de El Realejo, Chinandega. 2016, Hora 5:30 pm (Fotografía: Nelson García)

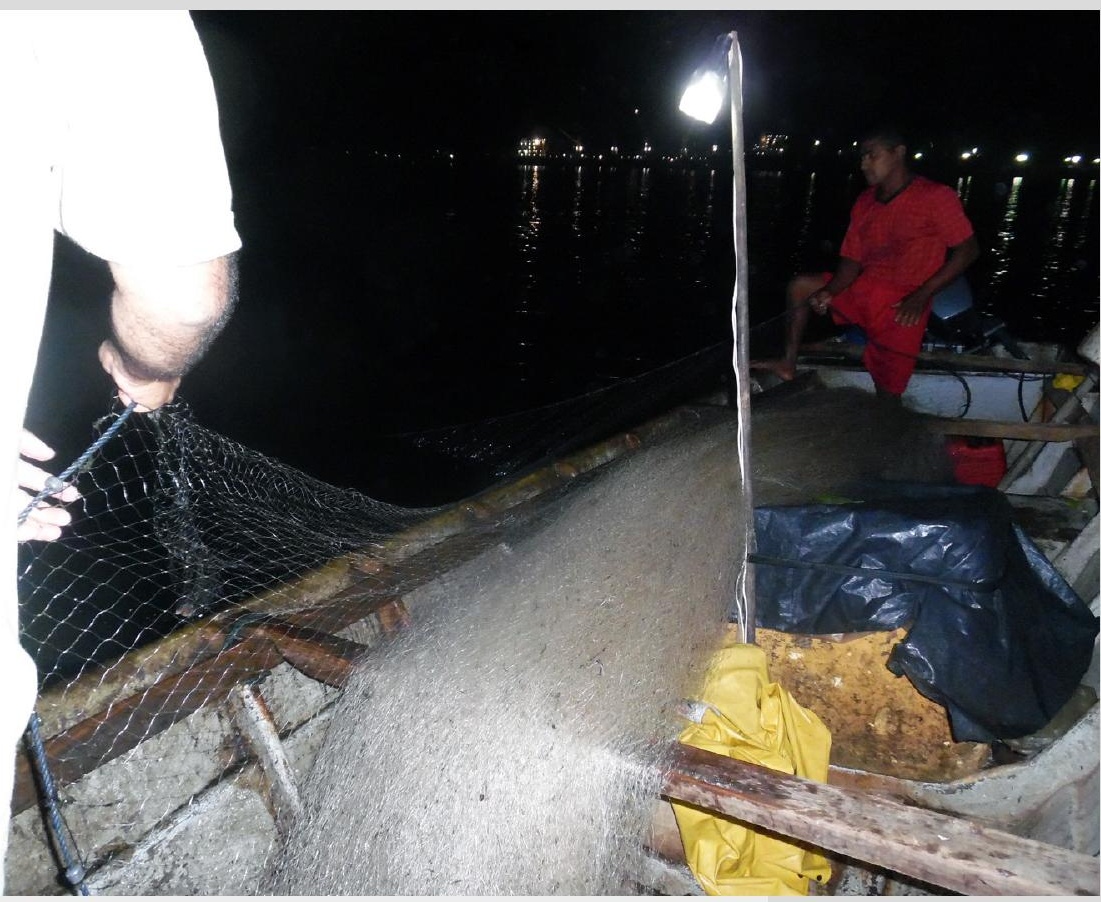

Pescadores en el proceso conocido como "levantar el trasmallo". Municipio de El Realejo, Chinandega. 2016, Hora: 10 pm (Fotografía: Nelson García) 


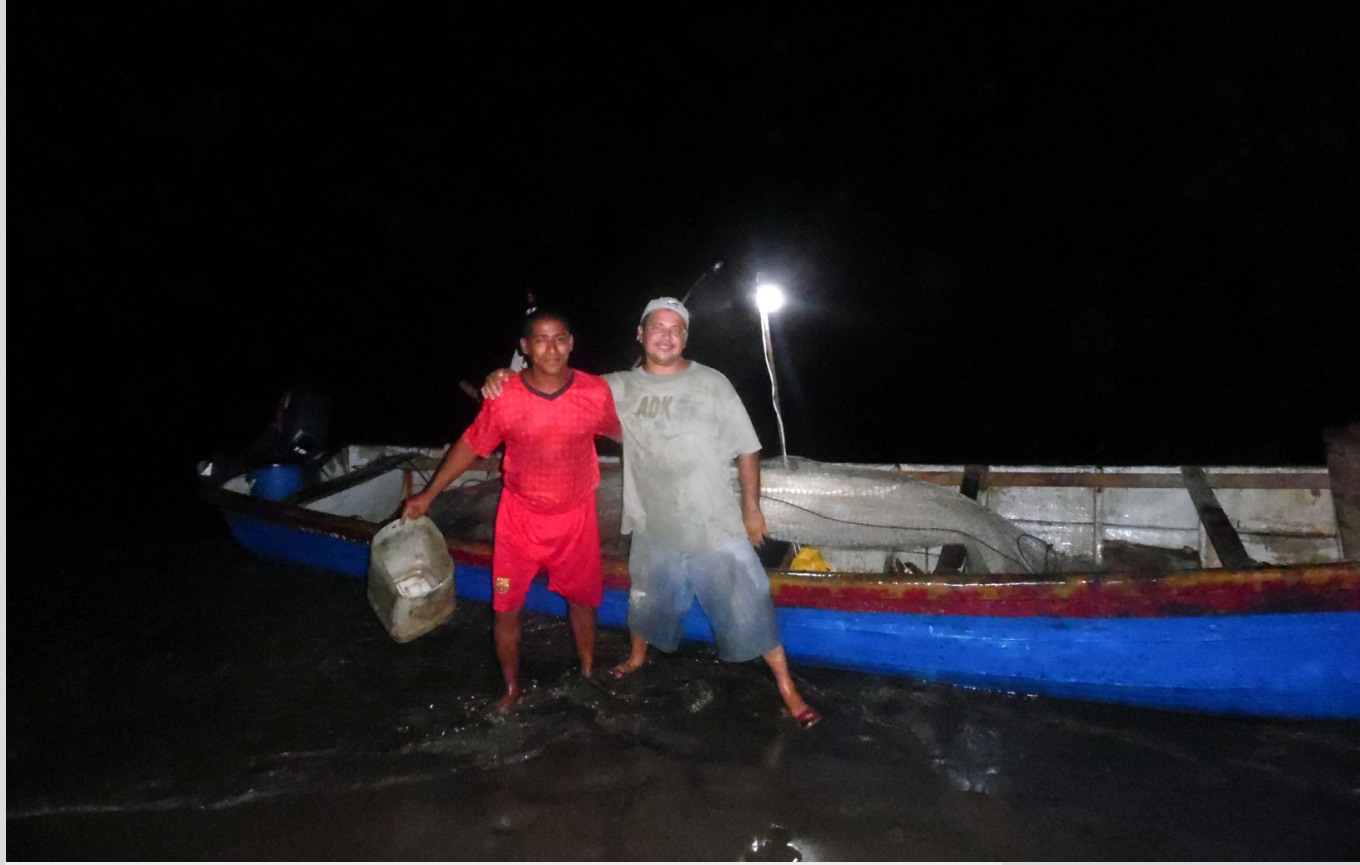

Pescadores Realejeños ubicados en Castañones, listos para salir en busca de otros puntos de pesca. Municipio de El Realejo, Chinandega. 2016, Hora: 2 am (Fotografía: Nelson García)

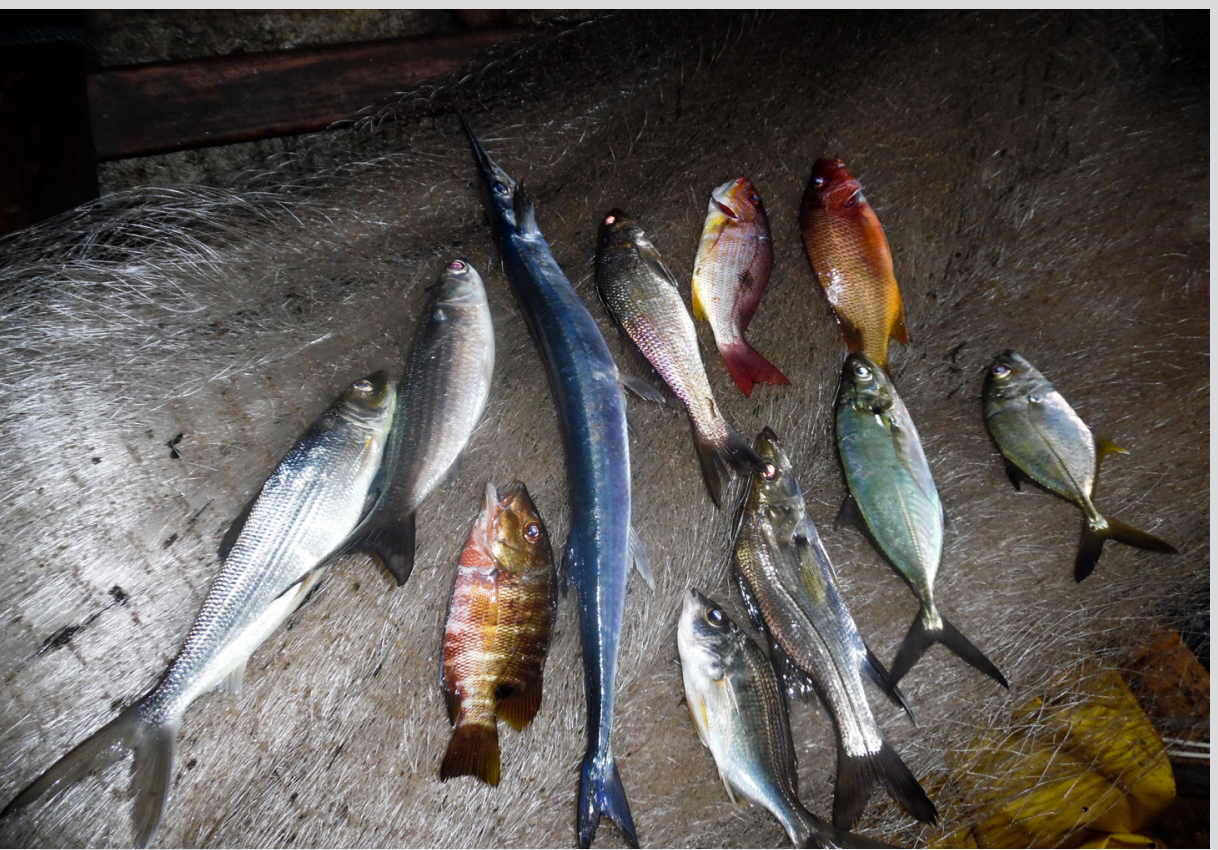

Parte de lo capturado en el trasmallo. Municipio de El Realejo, Chinandega. 2016 (Fotografía: Nelson García) 
